\title{
Haematological, Biochemical and Histopathological effects of Azathioprine in male guinea pigs
}

\author{
Ahlam A. Alrekabi ${ }^{1}$, Maitham A. Alrekabi ${ }^{2}$, Sawsan A. Alhasoon ${ }^{3}$ and Ahmad Nadim ${ }^{4}$ \\ aliabdalnaby19@gmail.com; dr.maitham79ali@yahoo.com; swasanalhasoon@gmail.com; \\ nomoalzubaidy@gmail.com \\ ${ }^{1}$ Department of Physiology, Pharmacology and Biochemistry, College of Veterinary Medicine, \\ University of Basrah, Iraq \\ ${ }^{2}$ Department of Clinical Pharmacology, College of Pharmacy, University of Basrah, Iraq \\ ${ }^{3}$ Department of Histology and Anatomy, College of Veterinary Medicine, University of Basrah, \\ Iraq \\ ${ }^{4}$ College of Veterinary Medicine, University of Basrah, Iraq.
}

\begin{abstract}
The study was conducted to evaluate the effects of azathioprine on hematologic, biochemical parameters, enzyme activities and histopathological changes on the leg bone, liver, kidney and testes. Two groups of pigs were used. Group 1 was given normal saline and group 2 was given azathioprine $(50 \mathrm{mg} / \mathrm{kg})$ orally over 4 weeks. The results indicate that azathioprine elicited a significant decrease in blood tests. While, the serum enzymes levels significantly increased in the albumin, urea and creatinine, histopathologically the leg bone exhibited a decrease in hematopoietic cell and an increase in adipocytes in the bone marrow. The liver showed vacuolation of hepatocytes, septal fibrosis and kidney presence vacuolation of cortical areas and dilatation of tubules. In testes, vacuolation and suppression of spermatogenesis in the treated group with azathioprine were noted. It can be concluded that azathioprine induces toxic and hazardous effects on some organs that restrict its use.
\end{abstract}

Keywords: Azathioprine, Hematologic, Biochemical, Histopathological, male pigs

\section{Introduction}

Azathioprine (AZA) is widely used as an immunosuppressant to prevent rejection of transplanted organs following organ transplantation. It is also given for leukaemia, arthritis, autoimmune diseases and inflammatory bowel disease treatment. Azathioprine with corticosteroid is the best option to prevent organ rejection [1]. AZA is one of the purine analogues chemical class. Despite the widespread use of this drug, it has been observed that it has other effects such as suppressing the patient's lymphocytes, causing toxicity in the bone marrow, gastrointestinal tract, liver and increased exposure to infection [2,3]. Furthermore, prolonged treatment with AZA causes many types of tumours and produces mutagenic, genotoxic, and teratogenic $[4,5]$. 
The immunosuppressive activity of AZA is due to its ability to inhibit the delayed hypersensitivity reaction and its cytotoxicity is due in part to the incorporation of 6-thioguanine nucleotide for DNA that occurs during renal allotransplantation [6]. Mostly, immunosuppressive drugs cause anaemia and increase the production of lipid peroxides leading to an imbalance between oxidant-antioxidant which causes the liver and other organs to have oxidative damage [7,8]. This drug converts into 6-MP through reactions with glutathione rapidly and is absorbed as a prodrug for mercaptopurine. Mercaptopurine blocks the DNA producing enzymes thereby affecting cells with high dividing capacity like T and B lymphocytes [9]. Metabolic intercellular of 6-MP is noted for its inactive metabolites - 6-thioguanine nucleotide (6-TGN) and 6-methyl mercaptopurine (6-MMP) that elicit azathioprine immunosuppressive features. Azathioprine causes stimulation of the stressactivated protein kinase pathway and mitochondria dysfunction causing necrotic cell death in intact isolated rat mitochondria [10]. The current study is considered the first study to evaluate the adverse effects of azathioprine on organs in Basrah, Iraq. This work was aimed to estimate the effects of Azathioprine on blood and biochemical criteria and organs (bone, liver, kidney and testes) in male guinea pigs.

\section{Materials and methods}

Drug: Azathioprine (AZA) ( Imuran ${ }^{\circledR}$, aspen, Ireland). A commercially available formulation of AZA $50 \mathrm{mg} /$ tablet (batch number 707074, expire date 5/2022) were purchased from a local private pharmacy. It was dissolved in normal saline and administered at $50 \mathrm{mg} / \mathrm{kg}$ body weight.

\section{Procedure}

In the current study, twelve adult male guinea pigs weighing $(900 \pm 100 \mathrm{gm})$ were kept at room temperature $\left(22 \pm 2^{\circ} \mathrm{C}\right)$ with a $12 / 12 \mathrm{~h}$ light-dark cycle. The guinea pigs were kept in one cage for one week and supplied with food and water ad libitum.

The pigs were distributed into experimental and control groups with 6 pigs in the group as follows:

Group 1: The pigs in this control group were given $1 \mathrm{ml}$ of normal saline orally for four weeks.

Group 2: This group were given azathioprine $(50 \mathrm{mg} / \mathrm{kg}$. b. w) The azathioprine was dissolved in normal saline and introduce as single daily dose administered orally for four weeks, this dose was chosen as described by[11].

The pigs were fasted overnight and were anaesthetized by inhalation with the ether solution. Blood samples were collected from the heart of the experimental and control animals which was then put in test tubes for clotting at room temperature and centrifuged at $3000 \mathrm{rpm}$ for 10 minutes. The serum 
was separated and stored at $-20^{\circ} \mathrm{C}$ until it was needed for biochemical analysis. EDTA as the anticoagulant was used in other tubes to collect other blood samples for haematological parameters.

\section{Biochemical assay}

The activity of aspartate aminotransferase and alanine aminotransferase were measured according to the method of [12]. The Alkaline phosphatase activity (ALP) was assayed by the method [13]. While albumin and urea were measured using the following method [14]. The creatinine level was carried out using the Randox assay kit [15].

\section{Haematological assay}

All haematology analyses - TWB count, RBC count, PCV percentage and Hb concentration were performed using a standard procedure with the count 60 haematology analyzer, Genix \&USA.

\section{Histological preparation}

The leg bone, liver, kidney and testes were removed and immediately the tissues were put in $10 \%$ neutral formalin for fixation. The testes were placed in Bouin's solution and the bone was decalcified in $15 \%$ formic acids, then the fixed tissue (liver, kidney, testes and leg bone) were prepared for histopathological study according to the method by[16].

\section{Statistical analysis}

In this study, the results were expressed as a means \pm SE. The data was analyzed by using student's t-test. The difference was considered significant with Value of $\mathrm{P}<0.05$.

\section{Results}

Table 1. RBC count, WBC count, Hemoglobin concentration $(\mathrm{Hb})$ and PCV for the control group and the group treated by azathioprine (AZA). The data illustrated the effect of azathioprine on the average RBC count, WBC count, haemoglobin concentration and PCV in male pigs. It was indicated that the administration of azathioprine caused significant $(\mathrm{P}<0.05)$ reduction in blood criteria when compared with the control group.

\begin{tabular}{llcccc}
\hline Treated group & $\begin{array}{l}\text { RBCcount } \\
\times 10^{6} / \mathrm{mm}^{3}\end{array}$ & $\begin{array}{l}\text { WBC count } \\
\times 10^{3} / \mathrm{mm}^{3}\end{array}$ & Hb g/100ml & PCV\% \\
\hline Control N.S & $6.93 \pm 0.05 \mathrm{~A}$ & $5.80 \pm 0.46 \mathrm{~A}$ & $13.04 \pm 1.8 \mathrm{~A}$ & $46.40 \pm 2.16 \mathrm{~A}$ \\
AZA50mg/kg & $2.95 \pm 0.19 \mathrm{~B}$ & $3.02 \pm 0.13 \mathrm{~B}$ & $6.2 \pm 1.7 \quad \mathrm{~B}$ & $22.7 \pm 1.3 \quad$ B \\
B.W orally & & & & \\
\hline
\end{tabular}


The difference in the capital letters means statistical difference $\mathrm{P}$ value less than 0.05 compared with control.

Table 2. Serum AST, ALT and ALP levels of control group and group treated by azathioprine (AZA), the findings explained the impacts of azathioprine on the liver enzymes levels in male pigs. It was observed that the treatment with azathioprine produced significant $(\mathrm{P}<0.05)$ elevation of ALP, AST and ALT levels as compared with the control group.

\begin{tabular}{lllllll}
\hline Treated group & AST unit/L & & ALT unit/L & \multicolumn{3}{l}{ ALP unit/L } \\
\hline Control N.S & $27.18 \pm 2.80$ & B & $19.80 \pm 1.01$ & B & $36.41 \pm 2.12$ & B \\
AZA50mg/kg & $50.61 \pm 1.44$ & A & $43.08 \pm 1.81$ & A & $66.22 \pm 3.25$ & A
\end{tabular}

The difference in the capital letters means statistical difference $\mathrm{P}$ value less than 0.05 compared with control

Table 3. Serum Albumin, Urea and Creatinine levels of the control group and group treated by azathioprine (AZA). The result revealed the effect of azathioprine on the average of albumin, creatinine and urea in male pigs. It was shown that administration of azathioprine caused a significant $(\mathrm{P}<0.05)$ increase in albumin, creatinine and urea levels as compared with the control group.

\begin{tabular}{llllll}
\hline Treated group & Albumin mg/dl & $\begin{array}{l}\text { Creatinine } \\
\mathrm{mg} / \mathrm{dl}\end{array}$ & Urea mg/dl \\
\hline Control N.S & $2.23 \pm 0.11$ & B & $1.29 \pm 1.03$ & B & $22.57 \pm 0.78$ B \\
AZA50mg/kg & $3.79 \pm 1.33$ & A & $2.46 \pm 0.04$ & A & $37.04 \pm 1.04$ \\
B.W orally & & & & & A
\end{tabular}

The difference in the capital letters means statistical difference P value less than 0.05 compared with the control group. 


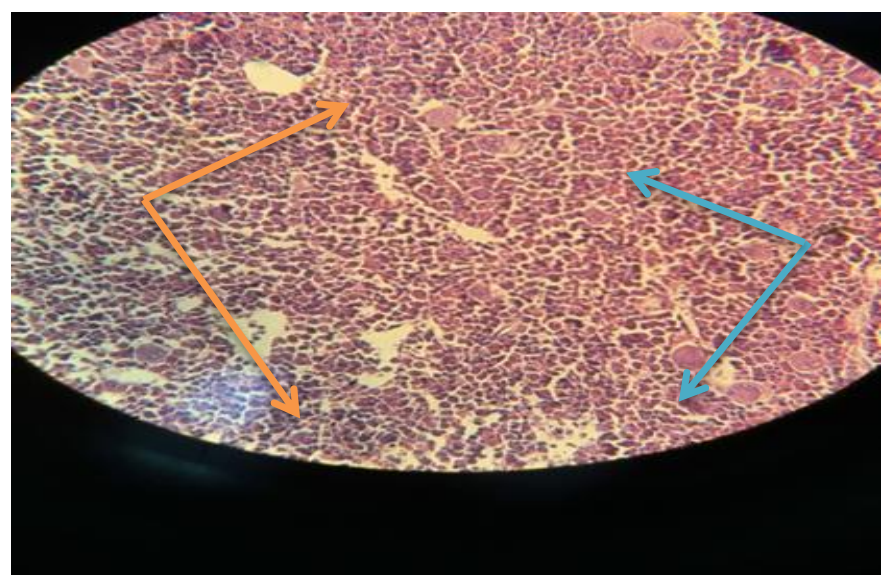

Figure [1] Leg bone marrow of a male guinea pig treated with normal saline showed hematopoiesis

$(\longrightarrow)$ and adipose tissue $(\longrightarrow$ within normal limits H\&E X400

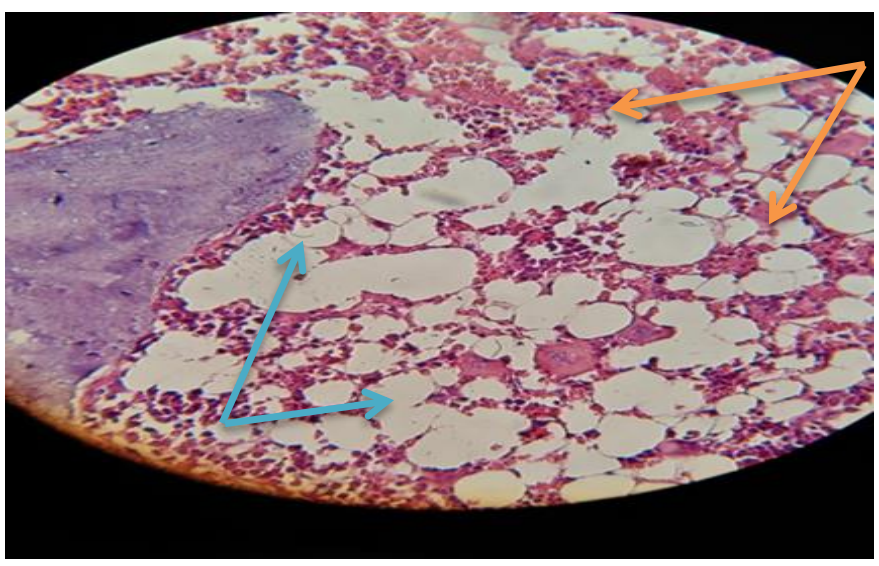

Figure [2] Leg bone marrow of a male guinea pig treated with azathioprine $(50 \mathrm{mg} / \mathrm{kg}$ ) for 4 weeks orally in this section showed that the administered azathioprine caused decreased hematopoiesis and congestion $(\longrightarrow)$ and presence adipose tissue $(\longrightarrow)$ H\&E X400. 


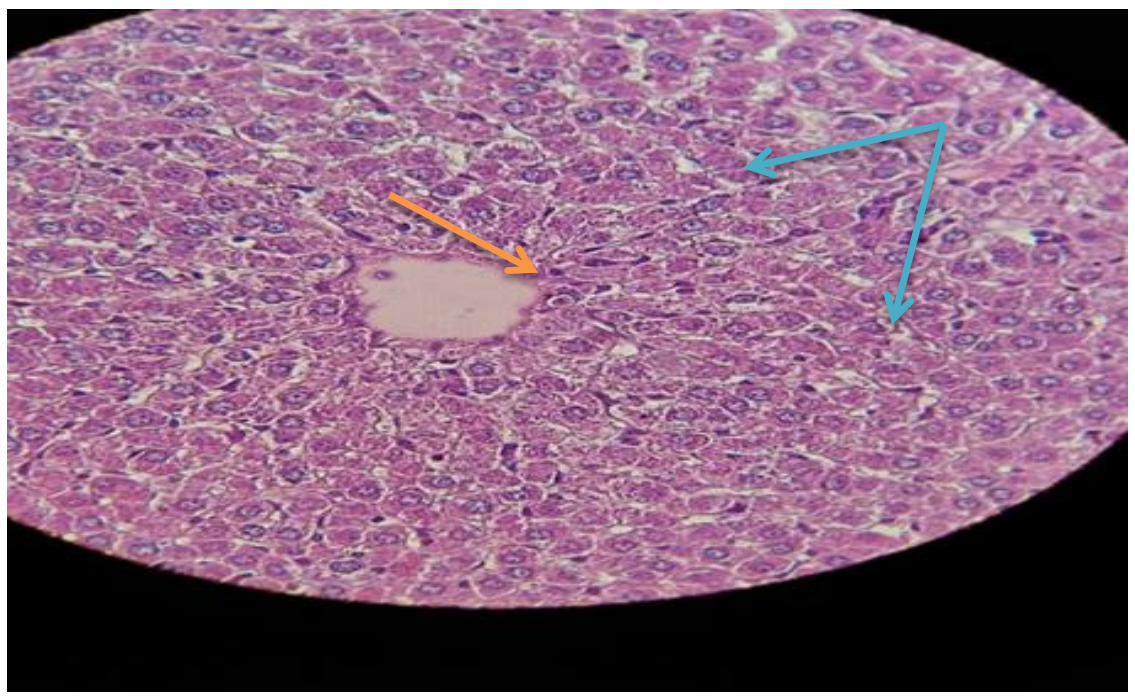

Figure [3] Liver of a male guinea pig treated with normal saline showed central vein $(\longrightarrow)$ and hepatocytes $(\longrightarrow)$ in normal limits H\&E X400 


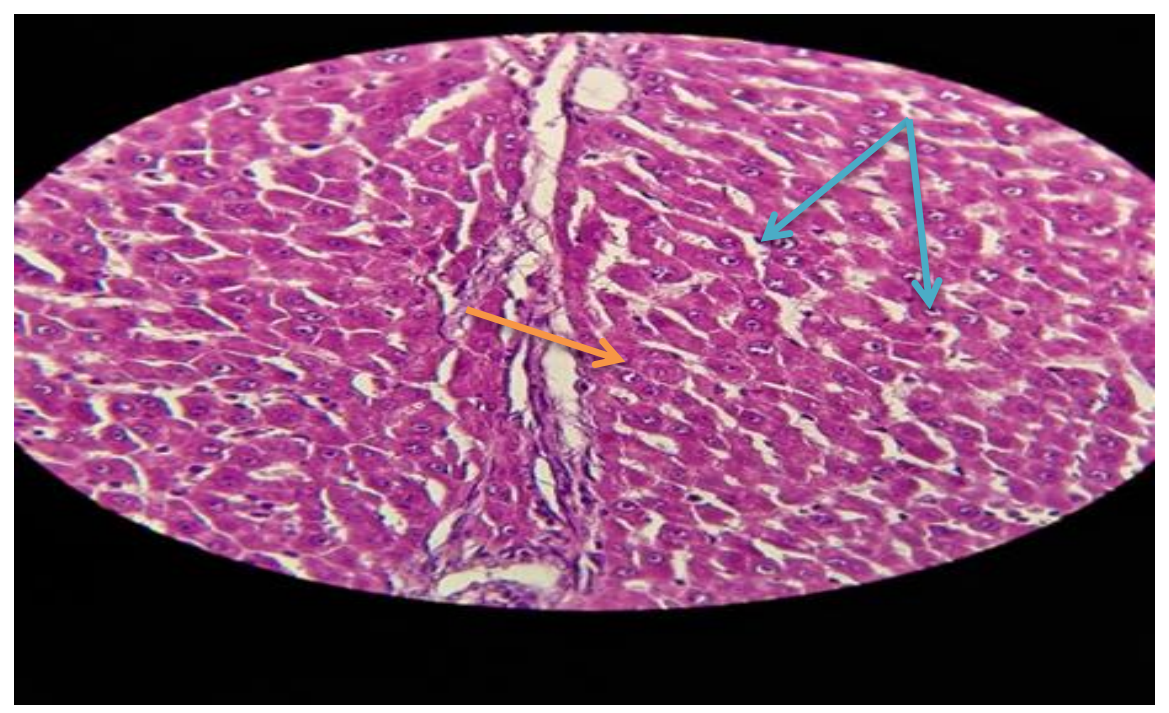

Figure [4] Liver of a male guinea pig treated with azathioprine $(50 \mathrm{mg} / \mathrm{kg})$ for 4 weeks orally, the section explained the administered azathioprine induced vacuolation of hepatocytes $(\longrightarrow)$ and septal fibrosis

$(\longrightarrow)$ H\&E X400.

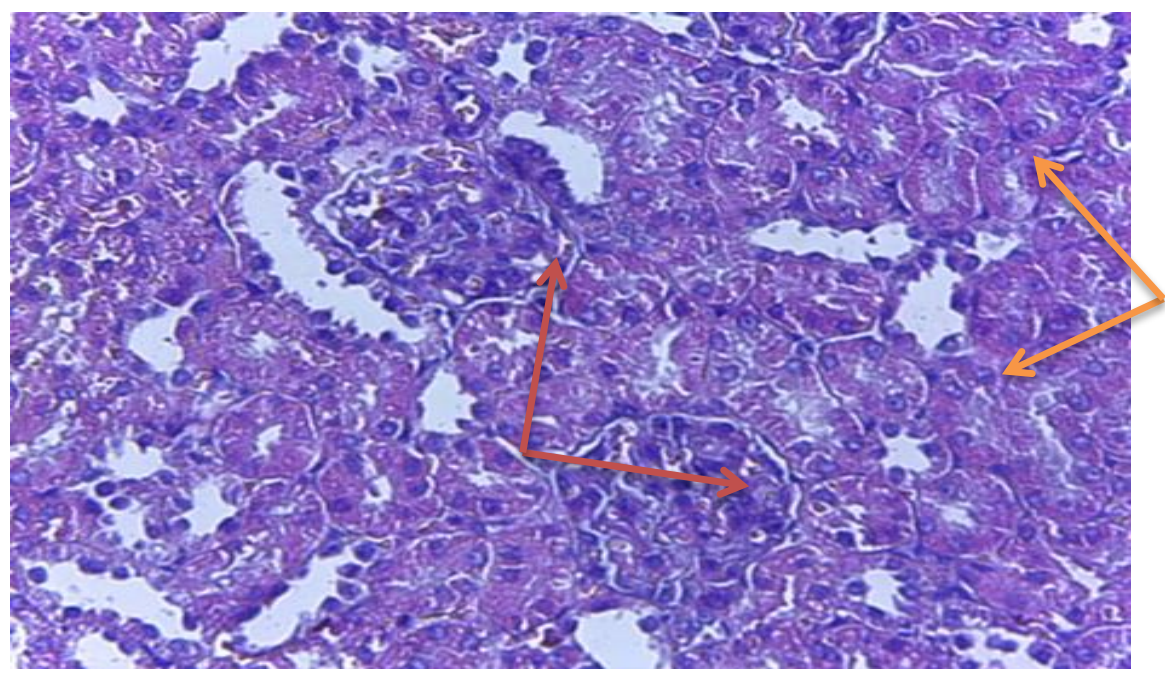


Figure [5] Kidney of a male guinea pig treated with normal saline, showed tubules of cortical areas $(\longrightarrow)$ and glomerulus $(\longrightarrow)$ within normal limits H\&E X400

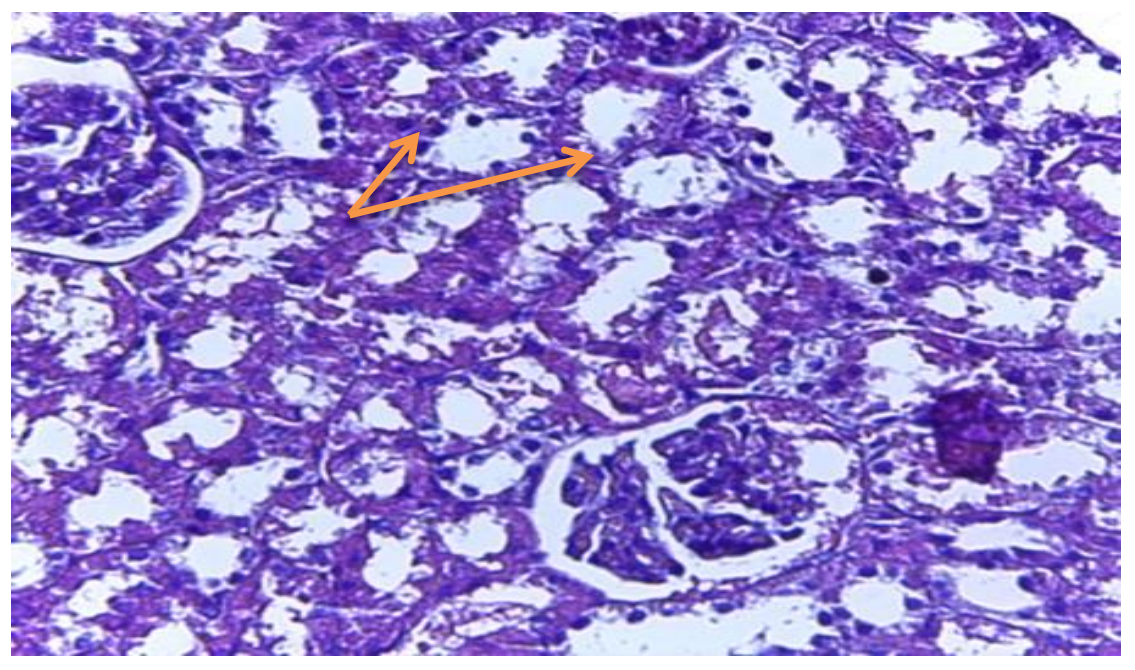

Figure [6] Kidney of male guinea pig treated with azathioprine $(50 \mathrm{mg} / \mathrm{kg}$ ) for 4 weeks orally, in this section showed vacuolation and dilatation of tubules of cortical areas after azathioprine administration $(\longrightarrow)$ H\&E X400. 


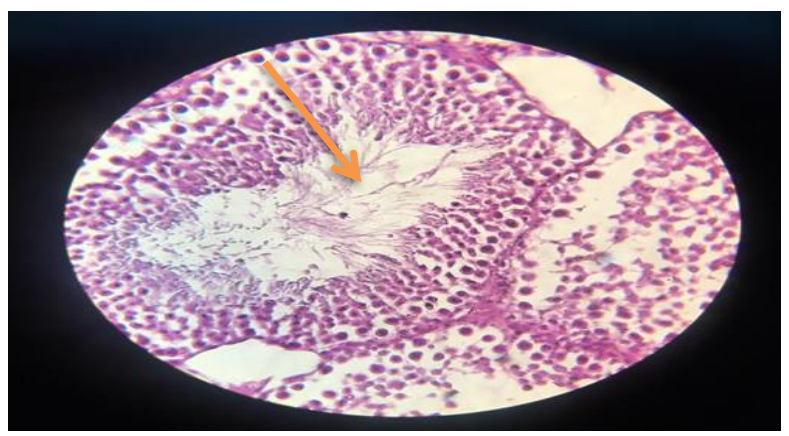

Figure [7] Testes of a male guinea pig treated with normal saline, in this section showed seminiferous tubules filled with spermatozoa $(\longrightarrow)$ H\&E X400.

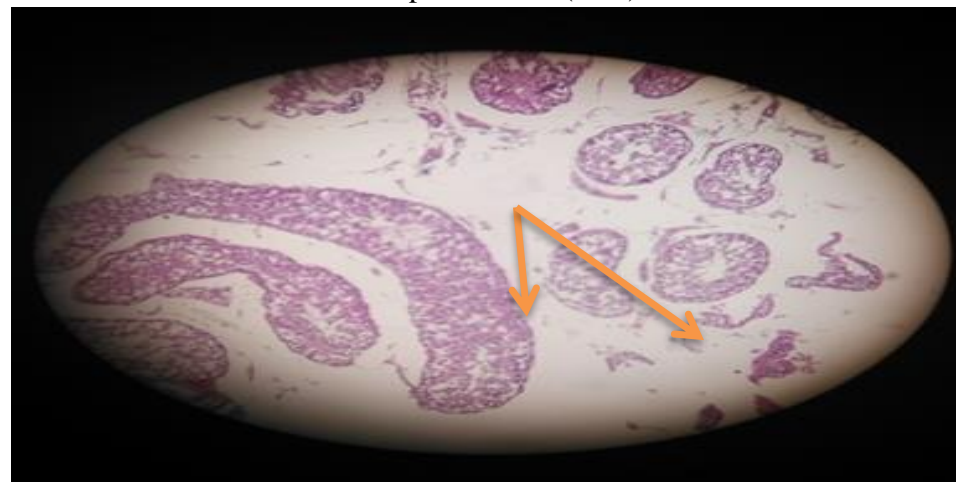

Figure [8] Testes of a male guinea pig treated with azathioprine $(50 \mathrm{mg} / \mathrm{kg})$ for 4 weeks orally, in this section showed vacuolation and suppression spermatogenesis after azathioprine administration $(\longrightarrow) \mathrm{H} \& \mathrm{E}$ $\mathrm{X} 400$. 


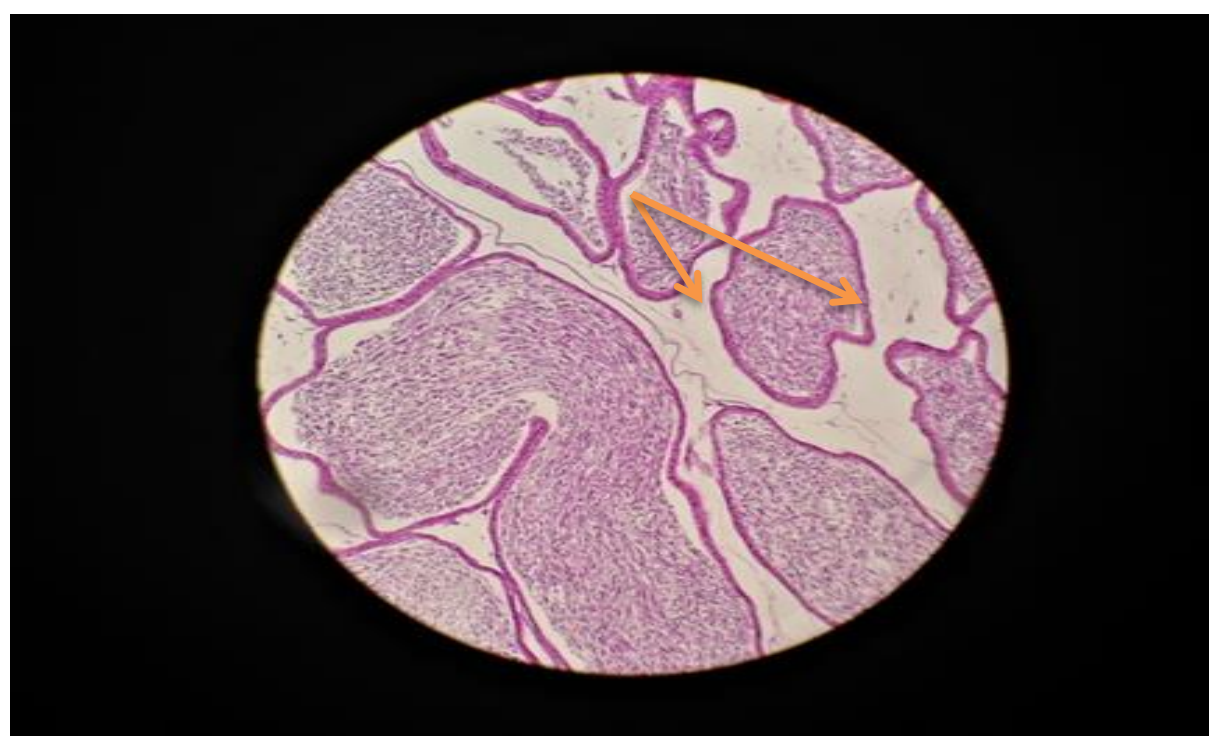

Figure [9] Epididymis of a male guinea pig treated with normal saline, showed lumen filled with spermatozoa $(\longrightarrow) \mathrm{H} \& \mathrm{E}$ X400.

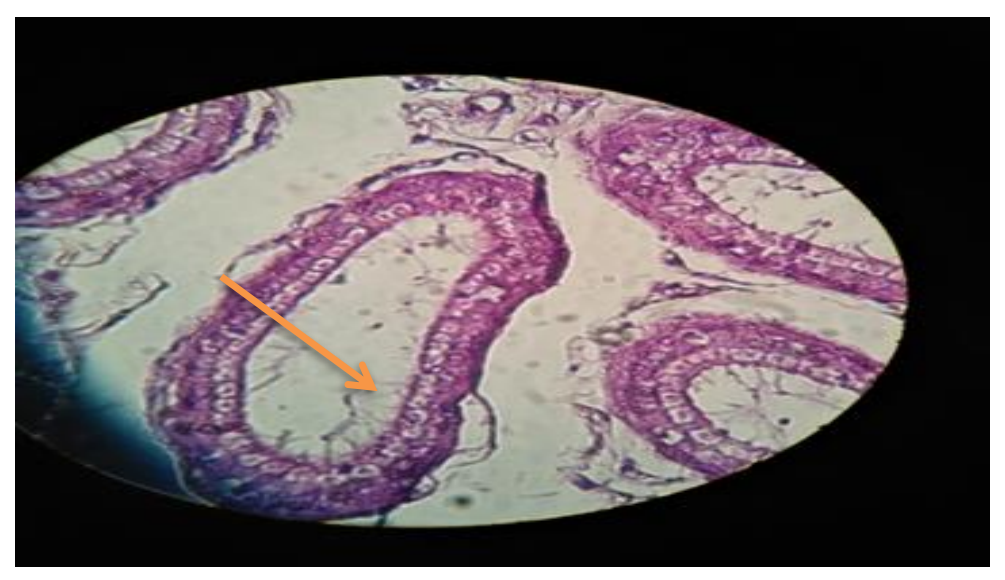

Figure [10] Epididymis of a male guinea pig treated with azathioprine $(50 \mathrm{mg} / \mathrm{kg})$ for 4 weeks orally, in this section showed the lumen empty from spermatozoa after azathioprine administration $(\longrightarrow) \mathrm{H} \& \mathrm{E} \mathrm{X} 400$. 


\section{Discussion}

Azathioprine is an immunomodulatory drug and is commonly used to that prevent rejection of transplanted organs and treatment of autoimmune system disorders [17].

Our results showed a significant reduction in the average $\mathrm{RBC}$, WBC count and haemoglobin concentration and PCV in guinea pigs treated with azathioprine compared with the control group. This indicates that the suppression of hematopoiesis may have contributed to anaemia [18]. Similar results with those obtained from previous researches[19,11] reported that the administration of azathioprine resulted in significant $(\mathrm{P}<0.05)$ reduction in the average $\mathrm{RBC}$ count, $\mathrm{TWBC}_{\mathrm{s}}$ count, $\mathrm{PCV}$ and $\mathrm{Hb}$ concentration. This is because azathioprine suppresses the bone marrow. It was found that the administration of azathioprine causes anaemia in rats which is characterized by a significantly lowered RBC and WBC values and decreased PCV and reticulocyte percentages [20]. Furthermore, the lymphocyte percentage and phagocytic activity were significantly decreased, causing toxicity in the bone marrow [21, 22].

The increasing of AST, ALT and ALP levels indicated liver dysfunction. The increase is due to the action of azathioprine toxicity on hepatocytes involves promoting the increase of reactive oxygen species (ROS) leading to mitochondrial injury, cell death and leakage of the enzymes from the liver cytosol into the blood [7,8]. This data agrees with the result of [2] who demonstrated that azathioprine administration induced hepatocytes damage is associated with changes in oxygen radical metabolism. The AZA-treated rats had an increase in hepatic lipid peroxides and this explains the observation of leakage of cellular APL, AST and ALT into the bloodstream due to liver injury. At the same time, there was a significant increase $(\mathrm{P}<0.05)$ in albumin, creatinine and urea levels in comparison with normal control pigs. This indicated that azathioprine administration causes kidney injury and this study was consistent with the expected results. It has previously been found that azathioprine-induced alterations in total the protein, urea and creatinine cause the elevation of urea and creatinine in the blood due to kidney dysfunction [23,24]. These waste products are passed into the bloodstream to be removed by the kidney.

The histopathological results found pronounced changes in the tissue (leg bone, liver, kidney and testes) which were seen after the administration of azathioprine in comparison with the control group. These changes were corrected with the haematological and biochemical alteration by using azathioprine. The results indicated that the free radical production and oxidative damage in organs and tissues were due to the toxicity of the drug [25]. These results are in agreement with other findings which showed that the reactive oxygen species is a potential source that could initiate oxidative stress and may be related to the production of some metabolites [26, 27]. This is because 6-mercaptopurine is a toxin and the generation of the reactive oxygen species decreased the ATP levels. GSH depletion, mitochondrial injury and cell death may be formed during their metabolism 
in hepatocytes. On the other hand [28,29] reported that the adverse effect of drug-induced hepatocytes and renal injury may be due to ammonia as it is highly toxic which is attributed to amino acids that are transformed into urea in the liver via acyclic mechanism and inner medullary nephron which causes reabsorption of the urine into the collecting tubes. From our results, the azathioprine administration caused oxidative damage to testicular tissues via lipid peroxidation and suppression of spermatogenesis. These findings are in agreement with [30, 31,1] who showed that the seminiferous tubules and disrupted epithelium cytoplasmic vacuolation, decreased diameters of seminiferous tubules and spermatozoa could not be distinguished of the lumen of seminiferous tubules. Our results revealed that the azathioprine might be responsible for alterations observed in the bone marrow histological with a progressive decline in the RBC and WBC counts in circulation which reflects active bone marrow suppression due to Azathioprine- induced toxicity. This finding is inconsistent with $[32,33]$ who found that a decrease in cellularity of hematopoietic cells and a corresponding increase in adipocytes in the bone marrow. The lymphocytes and lymphomas increase in the bone marrow and peripheral blood as occurs following exposure to cytostatic agents causing loss bone marrow cells.

\section{Conclusion}

According to the results obtained from this study, azathioprine has potential bone marrow toxicity as evidenced by anaemia, hepatotoxicity as evidenced by increased activities (AST, ALT and ALP), nephrotoxicity and suppression spermatogenesis at a dose $(50 \mathrm{mg} / \mathrm{kg} \mathrm{B.W})$ in male guinea pigs. Further study is required to assay the possible toxic effects of AZA on female guinea pigs, and how these toxic effects can be reduced.

\section{References}

[1] Dejaco, C.: Mittermaier, C.: Reinisch, W.: Azathioprine treatment and male fertility in inflammatory bowel disease. J Gastroenterol. Vol.121, PP1048-1053 (2003).

[2] Cesar, M.: Maria, D.: Fernandez, M.: Azathioprine acts upon rat hepatocyte mitochondria and stress-activated protein kinases leading to necrosis: protective role of $\mathrm{N}$-acetylcysteine. J Pharma Exper Therapy Fast Forward. Vol.104, PP 269-86 (2004).

[3] Wu, Y.: T.: Shen, C.: Yin, J.: P.: Meng, O.: Azathioprine hepatotoxicity and the protective effect of liquorice and glycyrrhizic acid. J Phytother Res.Vol.8, PP 640-645(2006).

[4] Marcen, R.: Pascal, J.: Tato, A.: M. Influence of immunosuppression on the prevalence of cancer after kidney transplantation. J Transplant Proc.Vol. 35, PP1714-1716(2003).

[5] Karawya, F.: D.: EL-Nahas, A.: F.: The protective effect of vitamin Con azathioprine induced seminiferous tubular structural changes and cytogenetic toxicity in albino rats. J Canc Therapy.Vol. 1, PP 125-134(2006). 
[6] Barbara, S.: Inflammatory bowel disease and male fertility. The Arthur Smith Institute Urology of the North Shore. J Heal Syst. PP 734-850(2010).

[7] Lee, A.: U.: Farrel, G.: C.: Mechanism of azathioprine -induced injury to hepatocytes: roles of glutathione depletion and mitochondrial injury. J Hepatol. Vol. 35, PP 756-764(2001).

[8] Farral, G.: C.: Toxicity of low dose azathioprine and 6-mercaptopurine in rat hepatocytes. roles of xanthine oxidase and mitochondrial injury. J Hepatol. Vol. 40, PP454-63(2004).

[9] Aninat, C.: Piton, A.: Glaise, D.: Charpentier, T.: Langouet, S.: Morel, F.: GuguenGuillouzo, C.: Expression of cytochromes P450, conjugating enzymes and nuclear receptors in human hepatoma HepaRG cells. J Drug Metab Dispos.Vol. 34, PP7583(2006).

[10] Maltzman, J.: Koretzky, G.: Azathioprine: old drug new action. J Clin Invest.Vol. 111, PP 1122-1124 (2003).

[11] Amin, A.: Hamza, A.: A.: Hepatoprotective effects of Hibiscus Rosmarinus and salvia on azathioprine induced toxicity in rats. J Life Sci. Vol.77, PP 266-78(2005).

[12] Mohammed, S.: M.: Ibrahim, M.: N.: Ahmed, M.:O.: Physiological and histological effect of broccoli on lead acetate induced hepatotoxicity in young male albino rats. Iraqi J Vet Sci.Vol.33, PP21-26 (2019).

[13] Wasfi, A.: A.: Abdul Razak, N.: K.: Eman, A.: Influence of silymarin extracted from Silybum Marianum seeds compared to logon against nickel chloride-induced haematological and biochemical changes in male rabbits. Bas Vet Res.Vol.14, (2015).

[14] Shahad, N.: Zaid, M.: M.: Effect olive oil and sesame oil on some biochemical parameters in local male rabbits induced with diabetes. Tikrit J Pure Sci. Vol.23, PP36-41(2018).

[15] Halil, A.: Ozlem, O.: Hamit, Y.: E.: Bunyamin, A.: Ercan, B.: Necat, Y.: The impact of gallic acid on the methotrexate-induced kidney damage in rats.J Food Drug Analysis.Vol.25, PP 890-894(2017).

[16] Mehran, K.: Javad, A.: M.: Mohammed, A.:A.: Fatemeh, S.: Emran, K.: Hossein, N.: Protective effect of alcoholic extract of garden cress seeds on the histopathological changes of the ventral prostate in streptozotocin-diabetic rats. Int J Morphol.Vol.35, PP1178-1184 (2017).

[17] Agarwal, P.: Agarwal, U.: S.: Meen, R.:S.: Sharma, P.: A combination of oral azathioprine and methotrexate in difficult to treat dermatoses.Indian J Dermatol Venereol Leprol. Vol. 83, PP 389-392(2017).

[18] Connel, W.: R.: Kam, M.: A.: Ritchie, J.: K.: Lennard-Jones, J.: E.: L.: Bone marrow toxicity caused by azathioprine in inflammatory bowel disease:27 years of experience. $\mathrm{J}$ Gut.Vol. 34, PP 1081-1085(1993).

[19]Danesi, R.: Del-Tacca, M.: Hematologic toxicity of immunosuppressive treatment. Transplant Proc. Vol. 36, PP703-704(2004). 
[20] Bendre, S.:V.: Shaddock, J.:G.: Patton, R.:E.: Dobrovolsky, V.:N.: Albertini, R.:J.: Heflich, R.: H.: C57BL/6mice treated chronically with azathioprine. J Mutat Res. Vol.578, PP114(2005).

[21] Maddocks, J.: L.: Lennard, L.: Amos, R.: Meyrick-Thomas, R.: Azathioprine and severe bone marrow depression. J Lancet. Vol. 1, PP 156(1986).

[22] Tabrizi, A.: B.: Mohajeri, D.: Dogstar, Y.: Biochemical and pathological study of the protective effect of vitamin A in azathioprine induced hepatotoxicity in rat. J Kashan Univ Med Sci. Vol.13, PP180-187(2009).

[23] Wang, X.: Wang, G.: Shang, J.: Pan, H.: Azhang, X.: Zhou, F.: Immunosuppression therapies adversely affect blood biochemical parameters in a patient with inflammatory bowel disease: a meta-analysis. J Int Med Res Vol.47, PP3534-3549 (2019).

[24] Dipiero, J.: Teg, K.: Hicks, J.: K.: Should thiopurine methyltransferase (TPMT) activity be determined before prescribing azathioprine, mercaptopurine or thioguanine, Cleveland. J Clin Med. Vol. 82, PP 409-13 (2015).

[25]Elelaimy, I.: A.: Elfiky, S.: A.: Hassan, A.:M.: Ibrahim, H.: M.: Elsatad, R.: I.: Genotoxicity of anticancer drug azathioprine (Imuran) role of omega-3( $\hat{\omega}-3)$ oil as protective agent.J Appl Pharmace Sci. Vol.2, PP14 (2012).

[26] Siramolpiwat, S.: Sakonlaya, D.: Clinical and histologic features of azathioprine - induced hepatotoxicity. J Gastroenterol Vol.52, PP 876-880 (2017).

[27] Ardeshiri, R.: Ghassemi, F.: Kargar, H.: Histological study of azathioprine effect on the liver in insulin-resistant rats. J Adva Enviro Bio. Vol.6, PP 2784-2790 (2012).

[28] Ansari, A.: Hassan, C.: Duley, J.: Thiopurine methyltransferase activity and the use of azathioprine in inflammatory bowel disease. J Alim Pharmacol Thera. Vol.16, PP17431750 (2002).

[29]El-Beshbishy, H.:A.: Trak, O.: M.: El-Bab, M.: F.: Autifi, M.:A.: Antioxidant and antiapoptotic effects of green tea polyphenols against azathioprine induced liver injury in rats. J Patholo Physiol. Vol.18, PP 125-135 (2011).

[30] Iwasaki, M.: Ikehara, Y.: Murakami, K.: Mizuno, I.: Nakagawa, O.: Fuse, H.: Analysis of Leydig cell dysfunction caused by azathioprine in rats. J Fertil Steril. Vol.45, PP4347(2000).

[31] Akinlolu, A.: A.: Akinola, O.: B.: Khobe, P.: Obast, K.: Dada, O.: Azathioprine and methotrexate impaired testes the morphology and functions of the testes in adult Wistar rats. J Morphol Sci.Vol,31, PP75-81(2014).

[32]El-more, S.:A.: Enhanced histopathology of bone marrow. J Toxico Pathol. Vol. 34, PP 666-686 (2006).

[33] Kailo, L.: Hung, C.: M.: Chen, Y.:F.: Ko, W.:C.: Chu, C.:Y.: Tsai, T.: F.: Azathioprine induced severe bone marrow toxicity. Chun Shan South Road. PP7 (2008). 